\title{
“REDISCOVERY" OF A FORGOTTEN ORGANELLE, THE PRIMARY CILIUM: THE ROOT CAUSE OF A PLETHORA OF DISORDERS
}

\author{
Denys N. Wheatley \\ BioMedES, Leggat, Keithall, Inverurie, Aberdeenshire, UK
}

The primary cilium was recognised in the late $19^{\text {th }}$ century. Conclusive evidence of its existence required the advent of the electron microscope (1950s-1960s), after which its comparison with motile cilia of the $(9+2)$ variety was made by Sorokin. Although a small group of devotees researched the primary cilium from this period until the late 1990s, its function as a sensor (previously advocated by Tony Poole) was established because it produced $\mathrm{Ca}^{++}$transients in intracellular signalling. The pathobiological consequences of ciliary agenesis or dysfunction was emphasised in the mid 1990s. But it was only after the recognition that agenesis could be due to mutations in intraflagellar transport proteins several years later that the pathological sequelae were appreciated. Since the early 2000s, the primary cilium has now been implicated as having many functions in cellular behaviour and development, such that disorder in this almost ubiquitous organelle in many tissues of the body leads to an astonishingly wide range of symptoms, from polycystic kidney disease to Alzheimer's. This organelle, dismissed as vestigial or rudimentary by most cell biologists for well over a century, can no longer be ignored in almost any medical and development condition. There is also very much more to learn about the biology of this fascinating organelle. Biomed Rev 2013; 24: 1-7

Keywords: cilia, ciliophaties, aciliogenesis

"Nothing a cell does is without significance."

\section{INTRODUCTION}

Just over one hundred years had elapsed before the significance of a small organelle became properly recognised, and the last 13-14 years have seen it rise above the horizon to take centre stage in so many syndromes and disorders of the body that it leaves most scientists and doctors astonished. It is not as if its significance had not been repeatedly pointed out over many years by a few staunch supporters. Apart from key moments in its long history, thoroughly and thankfully recorded by Bloodgood (1), and my own mention of the 10 main landmarks since the 1960s (2), we have to recognize that Poole et al (3) had shouted from the roof-tops about its significance and putative role decades ago, but their words fell on deaf ears - oth-

Received 11 November 2013, revised 27 November 2013, accepted 29 November 2013

Correspondence to Dr Denys N. Wheatley, BioMedES, Leggat, Keithall, Inverurie, Aberdeenshire, UK.

E-mail: editor@biomedes.co.uk; 3232dnwd@gmail.com 
ers to whom the primary cilium as a vestigial or rudimentary structure was of no significance or interest. Admittedly there was speculation, but not wild speculation, since it was quite clear it would have a mechanosensory function, if nowhere else than in the kidney and possibly other tissues (cartilage). The two papers that began to clinch this matter were Schwartz et al (4) and Praetorius et al (5) who showed that it was mechanosensory and could send a signal to the cell, causing a (free) $\mathrm{Ca}^{++}$transient, which had been established at that time as a mediator of widespread influence on many intracellular signalling pathways.

My contention remains, as indicated by the opening aphorism, that this organelle must have had significance from the very start, and that the exceptionally long primary cilia in the renal epithelial cells first seen by Zimmerman around 1897, should surely have indicated a definite physiological role (see ref. 1). But it also became apparent from the universality and diversity of primary cilia in the cells of the body that they could equally well be intimately involved in the behaviour of many other cell types. What, for example, were they doing in every neuron of the brain (6)? As an experimental pathologist, one can often become aware of the significance of a normal process by first exploring its derangement and dysfunction, its pathology. What then would be the consequence in the kidney, the cartilage, and a myriad of other cell types if their primary cilia failed to develop (aciliogenesis), or were malformed or malfunctioned? The obvious conclusion would be a lot of associated pathology, as explicitly pointed out some years ago (7). This is exactly what has transpired, and one is now asking the question in almost all pathological syndrome these days - is the primary cilium involved?

\section{CILIOPATHIES: THE TWO TYPES}

We have entered the era of the ciliopathies. However, there are two distinct (exclusively so) types of cilia, the $9+2$ (motile) variety and the $9+0$ (non-motile) primary cilium (Fig.ure 1). The latter arises from the diplosome, the paired centrioles, long and mistakenly for many years thought to be pivotal in the process of dividing the cell into two daughters. This alone should have drawn close attention to the distal centriole's "appendage", the primary cilium in some many cell types.

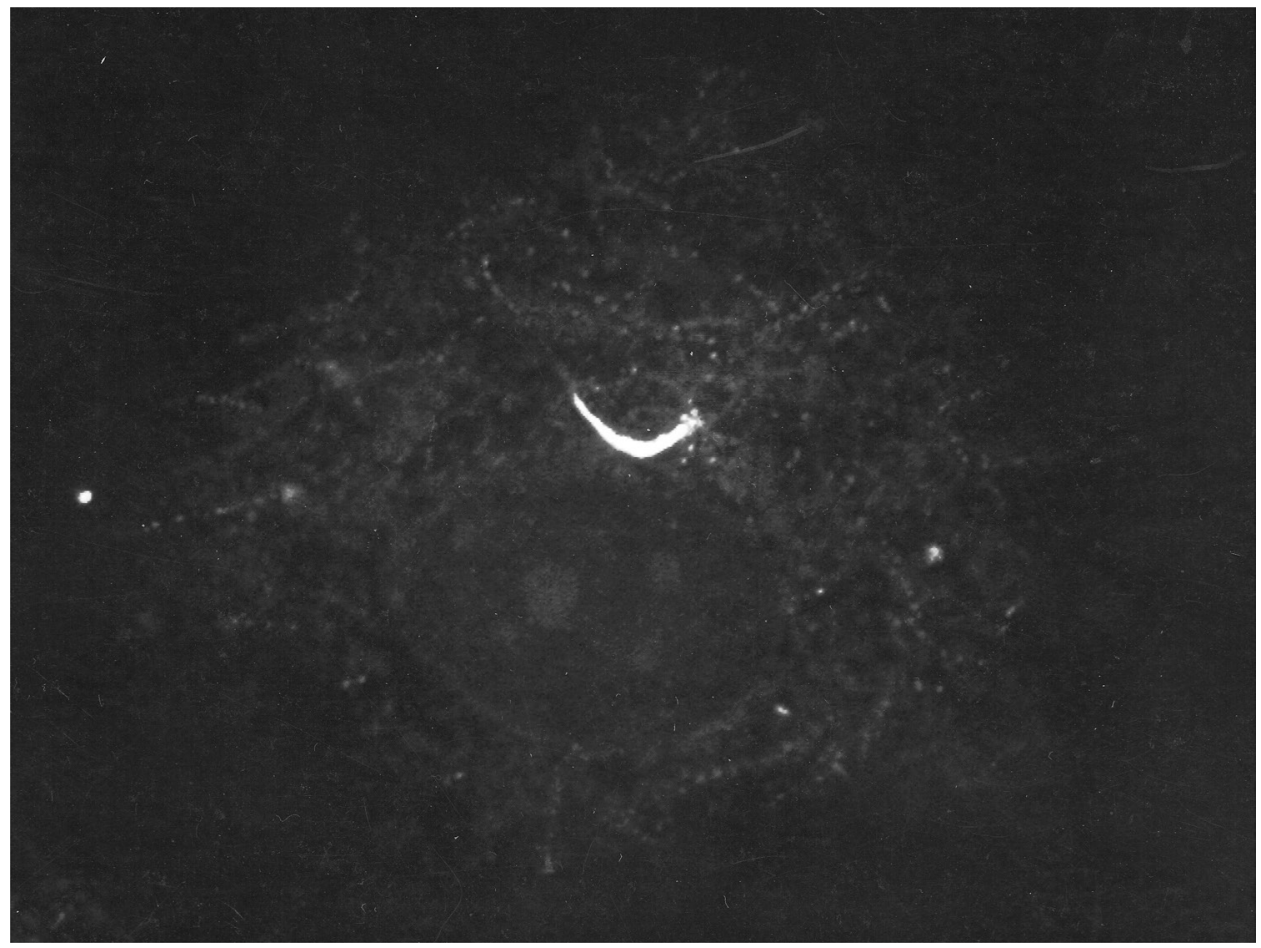

Figure 1. A bent primary cilium of a highly spread epithelial (PtK1) cell. It is brightly stained with a fluorescent conjugate to a gamma-tubulin antibody (ID5). The rest of the cell is faintly counterstained with a red fluorescent dye. Confocal scanning microscope image (average of 47 scans of whole cell); $x 7000$. 
Ciliopathies caused by loss of function of the motile variety have been known for decades, causing problems associated with oocyte movement, sperm motility, airway clearance, ventricular flow in the central nervous system, and so on. In medical conditions, these are referred to as primary ciliary dyskinesia, which is unfortunate because these do not involve primary cilia (the word primary in clinical use refers to the main cause of a disorder). But primary ciliopathies would need to be the connotation used for disorders involving the primary cilia and this is a bit of a mouthful. But this distinction most certainly needs to be made, unless by convention the former disorder can in future be referred to more simply as ciliary dyskinesia.

One of the first disorders thought to be attributed to aberration in the primary cilium was situs inversus totalis, as explored experimentally in developing mice by Nonaka et al (8), which has been a perplexing business over many years and may soon be better understood as involving both types of cilia (9). But it must also have been trenchantly obvious that blindness could be due to aciliogenesis since rods and cones of the retina are based on primary cilia (10). The organ that would be most likely to show malfunctioning as a result of primary aciliogenesisis the kidney (Fig.ure 2), and therefore it was not unexpected that they became strongly implicated in the disorder (along with other gene defects), known as polycystic kidney disease (PCKD), briefly reviewed in Ong and Wheatley (11). Because live births can ensue and life can continue with PCKD for some years, the finding nevertheless also suggests that the primary cilium can be of importance during development. If we fully explored this embryological aspect, it could probably be shown that primary cilium aciliogenesis, mutation or malfunctioning underlies much of inter-uterine death and congenital defects; Stiff et al (12) for example showed that in the inherited disorder, the Meier Gorlin syndrome, primary cilia poorly developed, and must be involved, along with other factors, in a condition that leads to stunted development. This can also be inferred from the increasing number of model organisms used in experimental developmental biology in which ciliary aberrations are disruptive in their development, e.g. Caenorhabditis elegans (13).

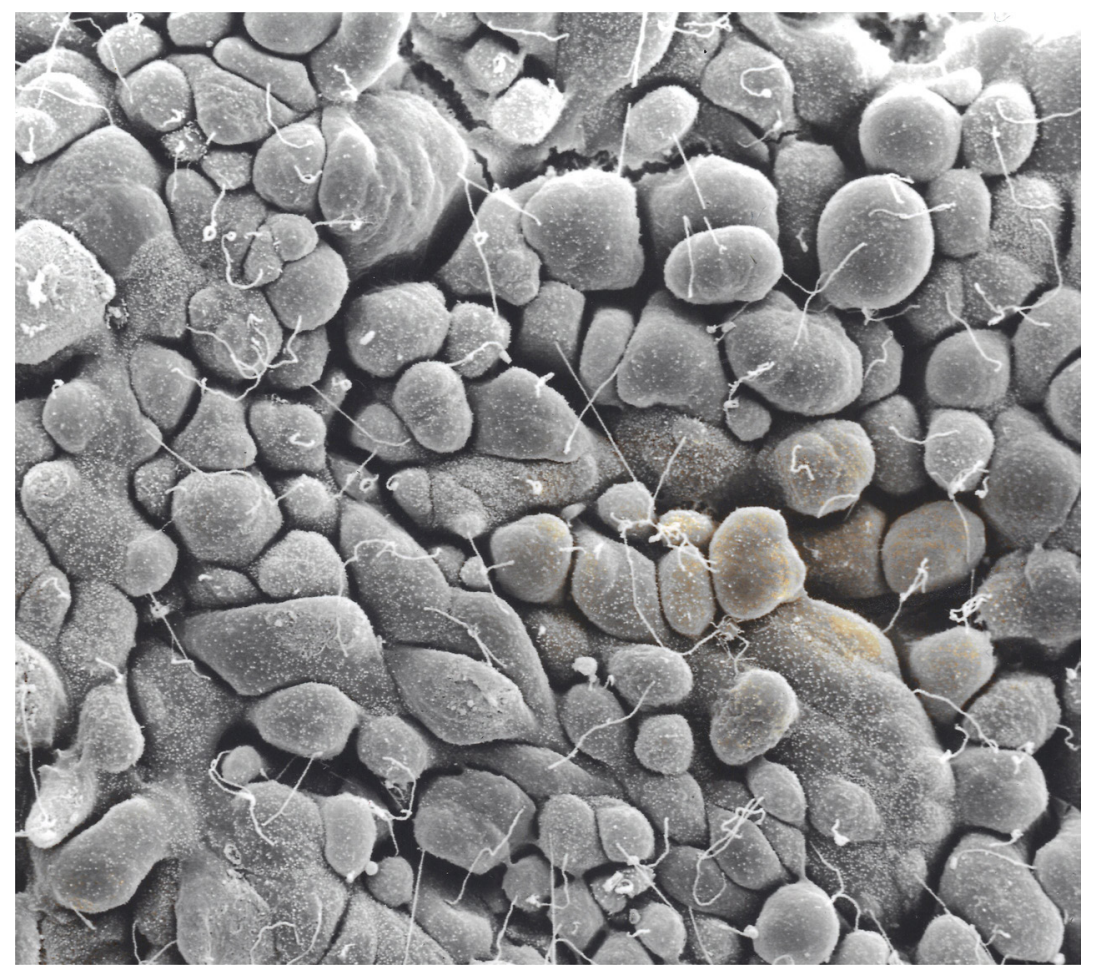

Figure 2. A cobblestone appearance of renal tubule epithelial cells (primary culture) which have not spread. Even so, they have very long cilia. Due to the changes (artefacts) in preparation for scanning electron microscope, the cilia can appear distorted rather than straight, but they are clearly very long; $x 2000$ 


\section{DISORDERS DUE TO PRIMARY CILIA: A DIFFICULT SEARCH}

The keywords needed to make a thorough literature search for references on primary cilia are difficult to set, and therefore each attempt misses many of them. Despite this drawback, there are now hundreds (possibly thousands) of reports each year on primary cilium biology, over half of which are not just interested in the basic cellular biology, but seek to understand the role of this "forgotten organelle" in a plethora of medical syndromes (Table 1).

If we were to put disorders in this list that have already been referred to before 2013 or cannot be mentioned here because of space limitation, my estimate is that we would end up with far greater than the number given in Table 1. This is nothing short of extraordinary, especially for an organelle that was largely ignored until after 1995.

Not all tissue cells show well-developed cilia - few can compare with those of the renal proximal tubule. But a question that has nagged me for years is why certain cell types seldom, if ever, develop primary cilia, i.e. apart from $9+2$ ciliated cells (14), which is based on the "exclusion" hypothesis, i.e. cells have either one or other type of cilia, and never both (15). These include blood borne cells such as lymphocytes and macrophages, which are suspended cells, although in comparing a strain of BHK12 cells that were adherent as monolayers in cultures with another that could be cultured and grow in suspension should have provided some clues, since the latter were far less frequently ciliated (Wheatley and MacPherson, unpublished data). Cells devoid of primary cilia also include some firmly fixed cells, like liver parenchymal cells. The basic cell biological problem is to understand, however, what elicits the development of a primary cilium. Even cells that lack cilia in their fully differentiated form may pass through a ciliated progenitor stage, indicating that this is a signalling problem locked deeply away in the heart of differentiation during development. One issue that has not been adequately addressed is whether this progenitor expression means that stem cells are ciliated. The answer will be of particular interest (16).

Another question is the relevance or status of cilia that do in fact seem to be ill-formed in some tissue cells, i.e. how well developed they have to be to function properly in a cell. Some early images of fibroblast cilia led many to the belief that they were indeed rudimentary - a word unfortunately used by none other than Sorokin (14), who had done so much to describe very accurately the structure and the development of both 9

Table 1. Range of disorders intimated in $>200$ reports published in 2013 alone

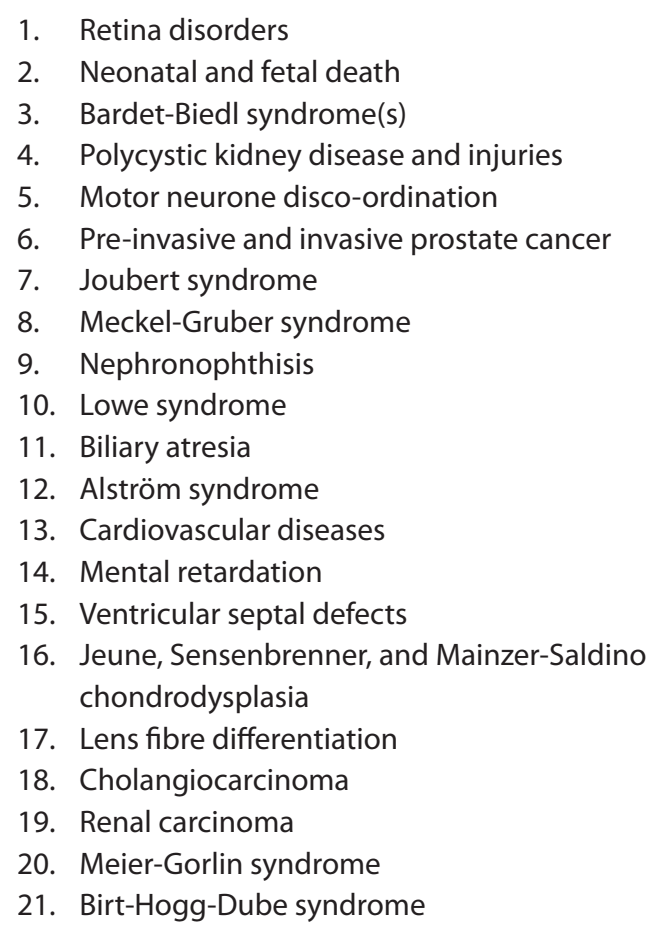

Many types

A multitude of disorders

Mesoaxialpolydactyly

Autosomal dominant and recessive

Absence of well-formed cilia

Multi-organ dysgenesis

Obesity, insulin resistance

Disorientation of fibres 
+2 and $9+0$ cilia. But there can be several explanations for incomplete development seen in some cells, the more obvious being that cilia are expressed during interphase of the cell cycle, and are almost invariably resorbed in division. They need to be regenerated each cycle (reviewed in 17), some believing that this may not occur until well into the next cycle. Thus, situations can be found where relatively poorly developed shafts appear as the cell moves quickly towards a second division (18).

\section{ON THE ASSEMBLLY OF PRIMARY CILIA}

The cell and molecular biology of primary cilia took off, along with a better understanding of the way in which cilia are constructed, by coming once again from a problem, a developmental defect, in their assembly. An intraflagellar transporter, IFT88, had a mutant form (Tg737) found by Doug Cole (19). This defect stops ciliogenesis, no matter whether it is of the 9 +0 or $9+2$ type. This was the breakthrough that led the way to showing that primary cilia could no longer be ignored. It led the way to showing that they acted as much as chemosensors as mechanosensors (4), and in short, to the acceptance of another prediction, that primary cilia would be shown to be antenna that not only receive messages (signals), but also emit them (20). In modern day terms, we are all connected by our IT media interfaces; cells, as organised and intercommunicating individuals in the human body (with their number massively outnumbering the population of the world), had their system in place billions of years ago (Fig.ure 3). Cargoes in the assembly of the primary cilium traverse up between the membrane and the axonemes with the help of kinesin II in anterograde transport, and returning cargoes go by countercurrent retrograde transport with the help of dynein 2 (reviewed in $21,22)$. Inserted in the membrane are a vast array of receptor molecules and there must also be other sites from which signals are emitted. The primary cilium is the interlocutor of the cell, so important that it is their individual antennae through which they communicate with the rest of the world they experience, their microenvironments ("microexposome"). If you compare the length of a renal cilium (typically 10-30 micrometres, but possibly as long as 50 micrometres) in relation to our tallest communications antennae on the surface of the world, they are impressively gigantic, making the fact that most of the cell biological fraternity ignored them for nearly a century even more astonishing.
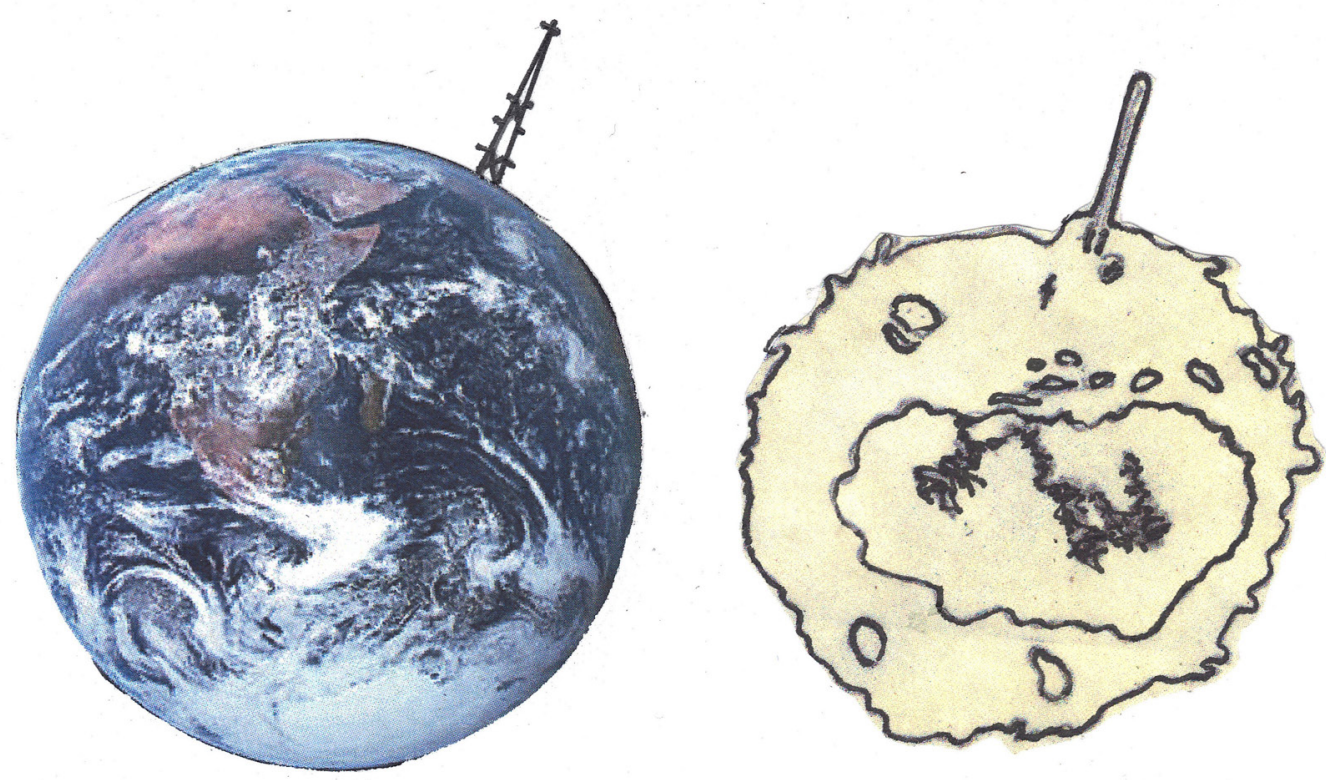

Figure 3. Illustration of the relative size of a primary cilium of a chondrocyte as its communication antenna compared with an analogous structure on the Earth. The latter would be 2500-2700 miles high, and 3 would be enough to cover the entire globe, i.e. giving them the same ability in communication as 3 satellites at the same height above the Earth. 


\section{QUO VADIS}

This is a brief review on an extraordinary cell organelle. Much is now written about its cell biology and its medical implications in the literature. Therefore it remains to consider where things will take us in the future. The one organ of the body in which primary cilia feature widely is the brain, with one cilium per neuron (6) and in almost every cell. There are implications that they are somehow associated with learning disorders, dyslexia, motor coordination, and obesity (as indicated in Table 1). There is therefore a hierarchy of signalling within signalling, from the intracellular level, to the intercellular level, to the inter-organ level, and to that between the organism and the entire environment. If things have gone this far, they can go further. It is not impossible that our forgotten organelle will finally be seen as playing a "pivotal" role in other theatres of life as well as neurological aberrations, just as further work on its place in the development of man and many other species will uncover an ever widening range of disorders.

\section{ACKNOWLEDGEMENTS}

None of this review would have been possible without the staunch support over the years of Sam Bowser, Tony Poole and many other too numerous to name. I am debited to Bob Bloodgood for setting the record straight, and I hope that future generations will appreciated that this once eclipsed organelle has now found its rightful place against all odds after a century of neglect. This should not happen again; we need to keep open minds on all life phenomena.

\section{REFERENCES}

1. Bloodgood RA. From central to rudimentary to primary: the history of an under appreciated organelle whose time has come. The primary cilium. Methods Cell Biol 2009;94:3-52. doi: 10.1016/S0091-679X(08)94001-2.

2. Wheatley DN. Landmarks in the first hundred years of primary (9+0) cilium research. Cell Biol Int 2005; 29:333-339.

3. Poole CA, Flint MH, Beaumont BW. Analysis of the morphology and function of primary cilia in connective tissues: a cellular cybernetic probe? Cell Motil 1985;5:175-193.

4. Schwartz EA, Leonard ML, Bizios R, Bowser SS. Analysis and modeling of the primary cilium bending response to fluid shear. Am J Physiol 1997; 272: F132-138.

5. Praetorius HA, Praetorius J, Nielsen S, Frokiaer J, Spring KR. Beta1-integrins in the primary cilium of MDCK cells potentiate fibronectin-induced $\mathrm{Ca} 2+$ signaling. $\mathrm{Am}$ J Physiol Renal Physiol 2004; 287: F969-978.
6. Dahl HA. Fine structure of cilia in rat cerebral cortex.Z Zellforsch Mikrosk Anat 1963;60: 369-386.

7. Wheatley DN. Primary cilia in normal and pathological tissues. Pathobiology 1995;63: 222-238.

8. Nonaka S, Tanaka Y, Okada Y, Takeda S, Harada A, Kanai $\mathrm{Y}$, et al. Randomization of left-right asymmetry due to loss of nodal cilia generating leftward flow of extraembryonic fluid in mice lacking KIF3B motor protein. Cell 1998; 95: 829-837.

9. Komatsu Y, Mishina Y. Establishment of left-right asymmetry in vertebrate development: the node in mouse embryos.Cell Mol Life Sci 2013; 70:4659-4666.

10. Sjöstrand FS. The ultrastructure of the inner segments of the retinal rods of the guinea pig eye as revealed by electron microscopy. J Cell Comp Physiol 1953; 42: 45-56.

11. Ong AC, Wheatley DN. Polycystic kidney disease - the ciliary connection. Lancet 2003;361:774-776.

12. Stiff T, Alagoz M, Alcantara D, Outwin E, Brunner HG, Bongers EM, et al. Deficiency in origin licensing proteins impairs cilia formation: implications for the aetiology of Meier-Gorlin syndrome. PLoS Genet. 2013;9, e1003360doi: 10.1371/journal.pgen.1003360.

13. Müller RU, Zank S, Fabretti F, Benzing T. Caenorhabditiselegans, a model organism for kidney research: from cilia to mechano sensation and longevity. Curr Opin Nephrol Hypertens 2011; 20, 400-408. doi: 10.1097/ MNH.0b013e3283471a22

14. Sorokin SP. Centrioles and the formation of rudimentary cilia by fibroblasts and smooth muscle cells. $J$ Cell Sci 1962: 15, 363-373.

15. Wheatley DN, Wang A-M, Strugnell GE. Expression of primary cilia in mammalian cells. Cell Biol Int 1996; 20: 73-81.

16. McMurray RJ, Wann AK, Thompson CL, Connelly JT, Knight MM. Surface topography regulates wnt signaling through control of primary cilia structure in mesenchymal stem cells. Sci Rep 2013;3:3545.

17. Goto H, Inoko A, Inagaki M. Cell cycle progression by the repression of primary cilia formation in proliferating cells. Cell Mol Life Sci 2013;70:3893-3905.

18. Ho PT, Tucker RW. Centriole ciliation and cell cycle variability during G1 phase of BALB/c 3T3 cells.J Cell Physiol. 1989;139: 398-406.

19. Pazour GJ, Dickert BL, Vucica Y, Seeley ES, Rosenbaum JL, Witman GB, et al. Chlamydomonas IFT88 and its mouse homologue, polycystic kidney disease gene tg737, are required for assembly of cilia and flagella. $J$ Cell Biol 2000;151:709-718. 
20. Wheatley DN. Another decade of advances in research on primary cilia, porosomes and neosis: some passing thoughts at 70. Cell Biol Int 2010; 34, 335-337.

21. Pedersen LB, Veland IR, Schrøder JM, Christensen ST. Assembly of primary cilia. Dev Dyn 2008;237:1993-2006.
22. Wheatley DN. Nanobiology of the primary cilium paradigm of a multifunctional nanomachine complex. Methods Cell Biol 2008; 90,139-56. doi: 10.1016/S0091679X(08)00807 